\title{
Taking Initiative in Addressing Diversity in Medicine
}

\author{
Nelson Saddler ${ }^{1}\left(\mathbb{D} \cdot\right.$ Seana Adams $^{1} \cdot$ Lisa A. Robinson $^{1,2} \cdot$ Ike Okafor $^{1}$
}

Accepted: 20 May 2021 / Published online: 21 July 2021

(C) Ontario Institute for Studies in Education (OISE) 2021

\begin{abstract}
The existence of systemic racism in Canadian healthcare, among other determinants including accessible education, available occupation, and affordable housing, contributes to the racial divide in treatment and poor health outcomes for Black communities. Recent promising work has demonstrated patient-physician racial concordance in populations of colour as a potential area of focus for addressing health inequities for diverse communities. The impact of shared cultural experiences and cultural competency leads to mutual respect, trust, and improved communication between patients and physicians guiding their care. This approach is dependent on the availability of physicians of colour and similarly other healthcare providers. The Temerty Faculty of Medicine at the University of Toronto has attempted to address the deficit in its own community through a two-pronged approach: mentorship through the Community of Support (COS) and the Summer Mentorship Program (SMP), and the implementation of the Black Student Application Program (BSAP). These initiatives have significantly increased Black medical student representation and continue to have considerable impact on Black communities in the surrounding area. Through partnerships with community organizations that support the ethos of these programs, the vision of a more culturally diverse physician workforce in Canada has been reinforced. The adoption of similar programs across Canadian medical schools can lead to better representation within medicine and help contribute to a necessary culture shift within the ranks of medical institutions. These are critical steps in laying the foundation for a medical education grounded in equity, excellence, and strength in diversity, and a healthcare system that truly provides patient-centred care.
\end{abstract}

Résumé La présence de racisme systémique dans les services de santé au Canada, qui compte parmi d'autres facteurs déterminants comme l'accès à l'éducation, les professions et les emplois disponibles, et le logement abordable contribue à la division raciale dans la qualité des traitements dispensés et les piètres conditions de santé des communautés noires. Des travaux récents et prometteurs ont démontré

Nelson Saddler

nelson.saddler@mail.utoronto.ca

1 Temerty Faculty of Medicine, University of Toronto, Medical Sciences Building, 1 King's College Cir, Toronto, ON M5S 1A8, Canada

2 Hospital for Sick Children, 555 University Avenue, Toronto, ON M5G 1X8, Canada 
qu'une concordance ethnique entre le patient et le médecin dans les populations formées de personnes de couleur pouvait s'avérer un champ d'intervention potentiel pour contrer les injustices en matière de santé touchant diverses communautés. Les expériences et les compétences culturelles partagées engendrent le respect mutuel, la confiance et une meilleure communication entre les patients et les médecins qui leur assurent des soins. Cette approche dépend de la présence de médecins de couleur et d'autres prestataires de soins de santé. La faculté de médecine Temerty de l'Université de Toronto a tenté de combler ce déficit dans sa propre communauté par une approche à deux volets: le mentorat par la communauté de soutien (CDS) et le programme estival de mentorat (PEM), et la mise en œuvre du programme de demandes pour les étudiants noirs (PDÉN). Ces mesures ont largement contribué à augmenter le nombre d'étudiants noirs en médecine et continuent d'exercer un impact considérable sur les communautés noires environnantes. Le partenariat avec les organismes communautaires qui s'alignent avec l'éthos de ces programmes a permis de consolider la vision d'un effectif de médecins plus diversifié sur le plan culturel. L'adoption de programmes similaires dans l'ensemble des facultés de médecine canadiennes peut mener à une meilleure représentation en médecine et contribuer à un changement de culture s'avérant nécessaire au sein des établissements médicaux. Ce sont des jalons indispensables pour jeter les bases d'une formation médicale fondée sur l'égalité, l'excellence et dans laquelle la diversité fait la force; et un système de santé qui fournit véritablement des soins centrés sur le patient.

Keywords Diversity $\cdot$ Health equity $\cdot$ Cultural competency $\cdot$ Medical school admissions $\cdot$ Racial concordance $\cdot$ University of Toronto $\cdot$ Black representation

\section{Racial Inequities in Healthcare}

The delivery of healthcare is not equitable in Canada. Structural racism embedded in healthcare institutions continues to contribute to the health disparities endured by Black communities, among other marginalized populations. This appears as historical, cultural, institutional, and interpersonal factors that negatively impact the ability of people of colour to access the same services and opportunities as their White counterparts, further perpetuating the racial hierarchy. The racial divide in healthcare is well documented in the USA; however, there is well-placed criticism concerning the dearth of race-based data in Canada. Increased attention has been placed on the social determinants of health as well as a focus on cultural competency in clinical encounters to complete a more thorough evaluation of a given patient. Recent work in Canada has demonstrated discriminatory practices reminiscent of disparities in the US healthcare system (Nnorom et al., 2019; Veenstra \& Patterson, 2016). Black Canadians face systemic barriers in accessing healthcare and are predisposed to worse health outcomes compared to White Canadians due to a host of socioeconomic factors including accessible education, available occupation, affordable housing, and scarcity of resources (Veenstra, 2019; Veenstra \& Patterson, 2016). Black patients and other marginalized populations can experience discrimination at any point accessing care whether this be overt racism or an under prioritization of their needs. This has been extensively documented in the perception and treatment of pain, in which Black patients are often undertreated (Chen et al., 2005; Drwecki et al., 2011; Goyal et al., 2015; Mossey, 2011; Staton et al., 2007). The occurrence of these discriminatory events may be due to conscious or unconscious biases and prejudices held by practicing physicians, and these deficits in cultural competency can shape attitudes toward physicians and healthcare in its entirety.

Medical mistrust is a prominent feature rooted within the Black community contributing to the aversion to medical intervention. The presence of persistent mistrust and contempt toward the healthcare system is evident (Hammond et al., 2010; Jacobs et al., 2006; King et al., 2004; Kinlock et al., 2017; Nanna et al., 2018), but this is not without just cause. The historic exploitation and experimentation on 
Black citizens in the name of medical innovation has sown widespread distrust in medical systems for these communities such as in the Tuskegee syphilis experiment by the US Public Health Service (Alsan \& Wanamaker, 2018) or the advances in diagnosis and treatment of gynaecological conditions at the expense of Black women who were enslaved (Thomas, 2009). Furthermore, Black people were considered "three-fifths of a person" and therefore sub-human by means of legislature before the abolishment of slavery (Lynd, 1966; Pope, 2015).

The pervasive mistrust of a medical system that has historically considered them as "other" and therefore expendable contributes to the difficulty those from Black communities have in establishing and then maintaining the patient-physician therapeutic alliance (Sellers et al., 2013). Despite these experiments being of the past, the chasm left between the Black community and doctors-who are most often not Black - remains. Though there are many possible solutions, racial concordance in healthcare interactions has been explored as one; medical schools are uniquely positioned to address this issue as the gatekeepers to the medical profession by creating a more equitable admissions process for prospective Black students. We will discuss the impact of a lack of racial concordance in healthcare in North America and particularly what the Temerty School of Medicine at the University of Toronto has done to address this issue via the Black Student Application Program.

\section{Racial Concordance in Healthcare}

Racial concordance has been proposed as a tool for bridging the divide between Black patients and physicians. The concept of racial concordance in the patient-physician relationship explores the potential benefits of shared identity between patients and physicians regarding their race, ethnic background, and/or culture. Subjective measures in the domains of communication, rapport, and satisfaction are commonly used within the literature to compare racial concordant or racial discordant patient-physician pairs in a clinical encounter. Several studies have found that Black patients report better experiences and increased satisfaction of care when interacting with Black physicians as opposed to White physicians (Arendt \& Karadas, 2019; Cooper et al., 2003; Hill et al., 2018; LaVeist \& Carroll, 2002; Laveist \& Nuru-jeter, 2018; Saha et al., 1999; Strumpf, 2011; Strumpf et al., 2020). Interestingly, the differences in perceived care or outcomes are not as striking for White patients in racial concordant pairs (Adamson et al., 2017; Greenwood et al., 2020). Black patients interacting with Black physicians reported better communication specifically in the areas of information-giving, shared decision making, partnership building, length of visit, mutual respect, and overall satisfaction of interaction (Shen et al., 2018). It should be recognized that rapport in the patient-physician relationship is progressively acquired and can be based on a long-standing relationship; this ever-evolving and complex history is not easy to quantify nor study. Therefore, the methodology of these studies instead utilizes a "first impression" scenario, which is equally as important to patients and especially relevant to those who lack a primary care physician, utilize urgent/emergency care as primary care, or those not able to regularly access care in general. It has been disputed how shared identity between patient and physician improves communication (Meghani et al., 2009; Sweeney et al., 2016), but the emergence of cultural competency as part of a physician's toolbox continues to improve patient relations and shared decision making.

In the USA, $60 \%$ of the difference in life expectancy between Black and White men can be attributed to chronic disease, in which primary and secondary prevention is essential to disease modification (Harper et al., 2012; Silber et al., 2014). In examining whether racial concordance influences demand for preventative care, significant increases in the use of health services, reductions in patient delay of seeking care, and compliance with screening tools like cholesterol monitoring have all been observed (Laveist \& Nuru-jeter, 2018; Strumpf et al., 2020). A study by Alsan et al. (2019) involving Black men as patients found that during medical encounters, they brought up more issues and sought more advice 
from Black doctors compared to White doctors; these same Black doctors in turn took more detailed clinical notes of the encounter compared to White doctors. In the pre-consultation stage, patients were informed of who their physician would be before meeting them and elected which preventative services they wished to receive. Patients randomly assigned to a Black physician requested similar preventative services preceding the clinical encounter compared to those assigned to a non-Black physician. However, upon interacting with their assigned physician, those assigned to Black doctors were significantly more likely to follow through with receiving these services, specifically those with more invasive means, i.e. blood work and immunizations (Alsan et al., 2019). The results of this trial readily demonstrate the ability of patient-physician racial concordance to establish trust, a cornerstone in medical management.

Hesitancy in disclosing personal information has been readily demonstrated in the literature when Black patients interact with mental health professionals (Klonoff et al., 1999; Klonoff \& Landrine, 1999; Sue et al., 2007). Issues of self-concealment have been partially attributed to cultural mistrust—an adaptive response deemed psychologically healthy developed by people of African descent as a result of negative experiences with White people, i.e. encounters that were culturally insensitive, prejudicial, or discriminatory in nature (Grier \& Cobbs, 1970). Consistent findings have detailed the preference for a same-race therapist including work by Thompson and Cimbolic (1978) indicating an increase in likelihood of utilizing mental health services if the therapist was Black (Thompson \& Cimbolic, 1978). In addition, the findings of Joseph (2010) were specific to Canadians of African descent, in which the preference for a therapist of African descent compared to a White therapist did not impact attitudes toward seeking treatment, yet it did increase willingness to seek treatment. The author suggests that specialized mental health services with racially similar staff may be more enticing due to the perception of a culturally safe environment (Joseph, 2010). Shared racial and/or cultural background may help to align worldview providing the therapist with insight to inherently understand sociocultural subtleties in presenting problems that otherwise would be more nuanced.

Communication is a critical component of medical encounters, and the cultural competency of a physician can enhance communication. Through shared decision making, patients may be more inclined to request or agree to preventative care in their medical management leading to benefits for patients, physicians, and the healthcare system. However, the question of whether these previously discussed proxy measures of the healthcare experience translate into improvements in long-term health outcomes is worth exploring. When highlighting the benefits of preventative care, Alsan et al. (2019) calculated that increased screening would lead to a $19 \%$ reduction in the Black-White male cardiovascular mortality gap and an $8 \%$ decline in the Black-White male life expectancy gap. The therapeutic alliance between patient and provider has more impact in some disciplines or specialties than others. A study by Hill et al. (2018) involved uninsured peoples hospitalized for a variety of medical issues, and randomly assigned to an attending physician of whom they had no prior relationship. In comparison to race discordant pairs, patient-provider race concordance led to a significant reduction in likelihood of inpatient mortality - that is to say, that a Black patient compared to a White patient of the same age and gender, with the same diagnosis, who lives in a similar area and is treated at the same hospital by the same physician, is $13 \%$ less likely to die when their physician is Black. This survival benefit enhanced to $15 \%$ in those with relatively severe and potentially life-threatening conditions (Hill et al., 2018). A striking finding from this investigation was that there was little to no evidence that White patients experienced negative impacts to their health when assigned to a race discordant physician; the decrease in inpatient mortality was exclusively found when Black patients were matched to Black physicians. The authors surmised that initial trust and resulting enhancements in communication and cultural competency-in combination with the previously mentioned observation that Black patients disclose more with race-concordant physicians (Alsan et al., 2019; Cooper et al., 2003; Gordon et al., 2006) - are main contributors to this disparity.

The reduction in inpatient mortality via race-matching physician is not restricted to adults. The existence of inferior health outcomes for Black newborns in the USA has been well researched (Burris \& 
Hacker, 2017; Collins \& David, 2009; Hauck et al., 2011; Villarosa, 2018; Wallace et al., 2017); recent work by Greenwood et al. (2020) elucidated this racial disparity in foetal outcomes and the significance of race-matching. Empirically, there is a reduction in the Black-White mortality gap when Black doctors care for Black newborns compared to White doctors. Racial concordance between newborn and provider elicited little benefit for White newborns, but for Black newborns, the likelihood of mortality was halved. This disparity is even more dramatic in medically complicated cases and in hospitals that delivered more Black newborns. Despite the evidence that Black birthing mothers suffer greater mortality than their White counterparts overall in the USA (MacDorman et al., 2017; Villarosa, 2018), no effect on the mortality of birthing mothers due to racial concordance with the physician was observed (Greenwood et al., 2020). This suggests that the manifestation of survival benefit for Black newborns extends beyond communication as the sole mechanism. The health disparities due to racial and ethnic backgrounds exist from birth and are compounded by the systemic racism those from Black communities are exposed to in their daily lives. Therefore, it is evident that action must be taken to increase minority representation in medicine to work toward improving overall health outcomes for patients.

Patient-provider racial concordance is not a panacea for health inequities within medicine. The misconstrued interpretation of these findings would be to support a system of segregated healthcare and perpetuate stereotypes and generalizations of race-based care. Instead, it should elucidate the health disparity that exists for Black individuals from birth to death. Healthcare is not provided for Black individuals the same way it is for White individuals, and the persistence of this health disparity means that Black communities will continue to suffer, and Black people will continue to die at a higher rate. The literary work of the past two decades, in addition to lived experience by Black communities, highlights the importance of communication, trust, and cultural competency in the patient-physician therapeutic alliance, and where efforts must be made to eradicate the racial disparities in the healthcare system. Patients from marginalized populations should be able to trust their White care providers and conversely, White doctors should be able to effectively provide for racialized patients. This review emphasizes the need for cultural and structural change - the training of more culturally competent doctors and similarly, the need for a diverse workforce to support this work. In doing this, society can advance toward the integration of marginalized populations historically exploited by structural racism in healthcare in order to provide true patient-centred care.

\section{The Approach to Diversity at the University of Toronto}

Increasing the representation of Black physicians is a crucial step towards improving the health outcomes for Black communities. Racial diversity among physicians and allied health professionals has demonstrated improved access to care for underserved groups and promotes the development of culturally informed care and breadth of health research for a given population (Cohen et al., 2002; Saha \& Shipman, 2006). Additionally, increased diversity in higher education institutions has been noted to deepen intellectual engagement and enhance skill development, benefiting fellow learners in medical education and colleagues in the workplace (Denson \& Chang, 2009; Valantine \& Collins, 2015). However, from 2014 to 2016, Black physicians made up just $4 \%$ of the physician workforce and less than $7 \%$ of recent medical school graduates in the USA, despite 13\% of the population self-identifying as Black. These numbers have not significantly improved as of recently, increasing a mere percentage point to 5\% in 2019. It is tempting to label this as a problem exclusive to our southern neighbours, but it must be understood that similar trends are reflected within Canadian medical institutions (Dhalla et al., 2002).

Toronto is hailed as one of the most multicultural cities in the world-home to a population in which 8.9\% self-identified as Black in the 2016 census (Statistics Canada, 2017), the highest proportion among metropolitan areas across Canada, and this number has continued to steadily increase each year. Yet in 
this same year, there was a single Black incoming medical student at the Temerty School of Medicine at the University of Toronto. Demographic data pertaining to race or ethnic background was not assessed during this application cycle, and thus, we are unable to provide data on how many Black individuals applied. Regardless, one student in a class of 259 is a disappointing $0.4 \%$ and not close to representing the community at large. Current inequities in income and education continue to be a barrier for Black residents and deter prospective students from pursuing STEM educative pathways. These inequities persist in the application process to medical schools whether by implicit (Capers et al., 2017; Goode \& Landefeld, 2019) or explicit bias as detailed in the Flexner Report (Flexner, 1910). This early twentieth century critique of medical education in North America led to the expulsion of Black students from medical education and subsequent closure of most medical schools at historically Black colleges and universities, the only schools that would train Black doctors, by the American Medical Association. The situation became so dire that by 1938 , Black medical students only represented $1.64 \%$ of the national student body (Borst, 2002). Similarly, there was a ban on Black medical students introduced by Queen's University School of Medicine in Kingston, Canada, in 1918, and though not formally enforced since 1965, it was not officially rescinded until 2018. Considering these restrictions imposed on aspiring Black students, it is difficult to precisely quantify the tens of thousands of Black doctors prevented medical training and resulting impact on generations to come. As written by Kamran Abbasi (1998) when acknowledging data on racial inequality in medical schools, "deans of medical schools should use [the data] as a catalyst for change instead of viewing criticism based on them as an assault on the credibility of their institutions" (Abbasi, 1998). The discriminatory practices in the medical admission process in addition to pre-existing disparities in income and education all contribute to the current paucity of Black physicians. The historical trend of disproportionately low representation of Black medical students at the University of Toronto served as the impetus for critically assessing the application process and subsequent creation of the Black Student Application Program (BSAP) (University of Toronto MD Program, 2021a).

The BSAP, which was in development even prior to the single Black student admission in 2016, was an initiative put forth by the Black Canadian Admissions Subcommittee at the University of Toronto as a response to the disproportionate number of Black medical graduates produced by its program. This program aimed to work synergistically with two pre-existing programs addressing inequities in accessing STEM education: The Summer Mentorship Program (SMP) (University of Toronto MD Program, 2021e) and Community of Support (COS) (University of Toronto MD Program, 2021b). These programs-developed in 1994 and 2005, respectively_work to provide mentorship to secondary school and post-secondary school underprivileged students. The SMP focuses on providing experiential learning opportunities for high school students, fostering interest in healthcare-related professions. Through COS, these prospective students then have access to admission information, academic counselling, research opportunities, and further support for each stage of the medical school application process including MCAT and interview preparation. These initiatives focus on the upstream engagement of students from high school to university, equipping them with the experiences and resources they may need to apply to medicine and other health-related disciplines. The final missing piece in these sequential support programs was therefore one that looked at the application process itself; thus, the BSAP was created.

The objective of the BSAP was to increase the accessibility of medical education for applicants coming from historically marginalized backgrounds, supporting students that self-identify as Black African, Black Caribbean, Black North American, and multi-racial students who identify with their Black ancestry. Modelled after the pre-existing Indigenous Student Application Program (ISAP) (University of Toronto MD Program, 2021d), the implementation of BSAP involved initial consultations with the Black community, critical assessment by faculty and staff, and final review and revisions with key stakeholders including Black Physicians of Ontario (BPAO), Black Health Alliance, and various campus and community presentations before its approval in 2016. The BSAP incorporates members of 
the Black community -including physicians, healthcare workers, and community members (i.e., allied health professionals, K-12 educators, career advisors, recruiters, outreach coordinators) - and facilitates their involvement in the admission process for students applying through the pathway. For those who choose to participate in this program, at least one self-identified Black individual is involved in reviewing their application, and if an interview is granted, it is conducted by at least one self-identified Black interviewer. Applicants are not treated preferentially. They must still meet exactly the same admission requirements (e.g. Medical College Admissions Test (MCAT) scores, GPA scores, autobiographical sketch, and supplementary essays) and undergo the same rigorous application process as students who apply through the general stream. Additionally, there are neither quotas for students who apply through BSAP nor any race-related quotas that apply to the incoming class of medical students. Therefore, this program does not lead to the preferential or mandated acceptance of Black applicants irrespective of merit. The message amplified through the implementation of this program rather is that Black students belong in medical education, and it is thereby imperative that they be proportionally represented in all levels of medicine, in addition to enriching the development and world view of their respective classmates.

Following its implementation into the 2018 admission cycle, the BSAP has been considered a resounding success-increasing the Black student population from 14 students accepted in 2018 to over 20 students accepted in 2020. The success of this program should not be solely indicated by the increase in Black learners, but the associated changes to the medical curriculum and contributions to the Black community in Toronto. This has been performed through the collaborative work of Black students as well as non-Black allies across all 4 years of the MD program under the Black Medical Students' Association (BMSA). The BMSA is actively involved in the curriculum development process, regularly ensuring that the content highlights equity and considers historically underserved populations. For example, dermatology content which primarily consisted of Caucasian skin now includes representation of conditions in people with darker skin tones. This shortcoming in the curriculum highlighted how medical students and thereby physicians were not being equipped with the tools necessary to identify and then treat darker skin individuals for common dermatological conditions. Furthermore, the University of Toronto MD Program appointed a Black Health Theme Lead, Dr. Onye Nnorom, to ensure appropriate modifications to the curriculum and fostering of other work groups to address the Black learner experience. These changes to the curriculum included an increased focus on the social determinants of health relevant to marginalized populations, anti-Black racism seminars, and workshops providing insight into microaggressions and cultural safety.

The gathering of BMSA members and allies for biweekly to monthly meetings provides the opportunity for peer support, career building, and a safe space to discuss any concerns of mistreatment by colleagues and/or staff. Following the identification of an issue, a collaborative statement can be issued to the faculty proposing an action plan for reparations and to advocate for change. The MD program has demonstrated their commitment to this by appointing a faculty member to a new anti-oppression role in conjunction with designing the MD Program Student Mistreatment Protocol—a confidential and anonymous process by which students can report mistreatment for further investigation (University of Toronto MD Program, 2021f). Several members of the BMSA are also part of a working group designated by the faculty to focus on the Black medical learner experience and ensure students feel supported from the time they enter medical school all the way until graduation. As an illustration of the unique insight and effectiveness of these groups, their advocacy for student wellness led to the acquisition of a mental health counsellor available to students with specialized training in microaggressions and anti-oppressive practices. Furthermore, the BPAO has connected with the BMSA to provide sessions on resiliency, strength, and healing as Black physicians and continues to work with the MD program to assist with mentorship through the pre-existing Diversity Mentorship Program (University of Toronto MD Program, 2021c) and provide scholarships and bursaries to students in financial need. BMSA meetings also 
provide opportunity for updates on collaborative events with university groups including the UofT Black Students' Association and community groups such as the Zero Gun Violence Movement. Finally, the BMSA facilitates the connecting of students to community outreach opportunities, highlighting where medical students can volunteer their time to support the Black community, i.e. community health centre events, vaccine mistrust initiatives and pandemic-specific initiatives including hygiene kit distribution. Cumulatively, these programs aim to help support Black students throughout medical school beyond the initial acceptance as well as connecting them with the Black community.

An initiative by the BMSA titled "Mental Health in the Black Community" ran from 2018 to 2020 and hosted professionals with extensive work in the field of Black mental health including psychiatrists, social workers, clinical psychologists, and doctoral researchers. These events created a platform whereby Black residents and allies from the community could congregate on campus to network, learn, and form partnerships with each other on the topic of mental health. These events gathered a total of 400 people, with nearly $80 \%$ identifying as Black, and information from these events was later shared by the BMSA at advocacy conferences to continue amplifying voices of the Black community. The BMSA continues to explore disparities that can be addressed by a keen group of medical students, early in their careers of becoming medical professionals, through partnerships with the Black Heath Alliance and community health organizations that focus on Black health including TAIBU and Black Creek.

Mentorship is another pillar of the BMSA and involves students working alongside the COS to host mentorship sessions and support underprivileged high school and undergraduate students interested in healthcare professions. Understanding the financial difficulty for those coming from lower SES households (Bandiera et al., 2015; Beagan, 2001; Lam et al., 2020), the most recent endeavour undertaken by the BMSA was the creation of the "Unofficial Guide to Canadian Medical School", a free-to-access medical admission roadmap (UofT Black Medical Students' Association, 2020). Created during the COVID-19 pandemic, this entailed the collaborative effort of over 70 medical students representing all 17 Canadian medical schools, coordinated by the BMSA to highlight how mentorship should never come at a financial cost.

The increase in Black medical students, associated changes to the medical school curriculum, and investment into the surrounding community can be attributed to the combined achievements of the COS, SMP, and the BSAP. However, these programs are no longer alone in the pursuit for increased diversity within admissions. Similar mentorship and application programs for medicine have been introduced at Queen's University, Dalhousie University, University of Alberta, and Cumming School of Medicine at the University of Calgary. Additionally, there is now a National Black Medical Students Association which coordinates networking, events, and financial support among Black medical students from coast to coast. Yet, the work toward equity in admissions and by extension equity in healthcare is not complete. There are a total of 17 medical schools in Canada, and issues with representation persist. At the University of Toronto, a remarkable increase to 10\% Black representation in the 2020 incoming class is a positive step but cannot repair the decades-long history of disproportionate numbers of Black graduates. In recognition of this, admission working groups at the University of Toronto continue to assess each step of the application process with an equity lens and evaluate the learner experience. It is also recognized that microaggressions and bias continue into residency (Osseo-asare et al., 2018), and recent data from the BPAO describes the differential treatment and racism from peers, superiors, and patients that Ontario physicians continue to experience well into their practice (Mpalirwa et al., 2020). Increasing representation is necessary, but a culture shift is essential to building a safe and inclusive workplace and a crucial step in the journey toward equity in healthcare.

Eliminating discriminatory practices in healthcare requires the incorporation of equity into the medical school application process. Whether through racial concordance, or other mechanisms including returning to work in underserviced areas (Grumbach \& Mendoza, 2008), and focusing on primary care specialities (Palepu et al., 2000), or the work here in Toronto, Black communities 
have better health outcomes when Black medical professionals are able to equitably facilitate care. Medical school classes that are proportionally representative of the population address societal need, and this has been demonstrated by the impact of the Community of Support, Summer Mentorship Program, and the Black Student Application Program. This could not have been done without putting a spotlight on underserved Black communities and integrating their voices into the admission process. By involving the community, admission committees will strengthen their commitment to health equity and anti-Black racism in medicine. This work is not complete, but the commitment by the MD program is demonstrated by the formation of a steering committee to solidify a living and breathing relational feedback loop between Black community members and the Faculty of Medicine with the goal of eliminating anti-Black racism in medical education. Ultimately, by following the examples put forth by the MD program at the University of Toronto-concurrent upstream initiatives while simultaneously addressing equity in the admission process and curriculum-other medical institutions can select a cohort that is not only diverse and representative of the population, but transformational and enriching for students, colleagues, physicians, patients, and communities combined.

\section{Declarations}

Conflict of Interest The authors acknowledge their affiliation with the University of Toronto medical program by status of medical student, admissions committee member, or faculty.

\section{References}

Abbasi, K. (1998). Is medical school selection discriminatory? Bmj, 317(7166), 1097-1098. https://doi.org/10.1136/ bmj.317.7166.1097

Adamson, A. S., Glass, D. A., \& Suarez, E. A. (2017). Patient-provider race and sex concordance and the risk for medication primary nonadherence. Journal of the American Academy of Dermatology, 76(6), 1193-1195. https:// doi.org/10.1016/j.jaad.2017.01.039

Alsan, M., Garrick, O., \& Graziani, G. (2019). Does diversity matter for health? Experimental evidence from Oakland. American Economic Review, 109(12), 4071-4111. https://doi.org/10.1257/aer.20181446

Alsan, M., \& Wanamaker, M. (2018). Tuskegee and the health of black men. Quarterly Journal of Economics, 133(1), 407-455. https://doi.org/10.1093/qje/qjx029

Arendt, F., \& Karadas, N. (2019). Ethnic concordance in patient-physician communication: Experimental evidence from Germany. Journal of Health Communication. https://doi.org/10.1080/10810730.2018.1549624

Bandiera, G., Maniate, J., Hanson, M. D., Woods, N., \& Hodges, B. (2015). Access and selection: Canadian perspectives on who will be good doctors and how to identify them. Academic Medicine, 90(7).

Beagan, B. (2001). Micro inequities and everyday inequalities: "Race," gender, sexuality and class in medical school. Canadian Journal of Sociology, 26(4), 583-610. https://doi.org/10.2307/3341493

Borst, C. G. (2002). Choosing the student body: Masculinity, culture, and the crisis of medical school admissions, 1920-1950. History of Education Quarterly, 42(2), 181-214.

Burris, H. H., \& Hacker, M. R. (2017). Birth outcome racial disparities: A result of intersecting social and environmental factors. Seminars in Perinatology. https://doi.org/10.1053/j.semperi.2017.07.002

Capers, Q., Clinchot, D., McDougle, L., \& Greenwald, A. G. (2017). Implicit racial bias in medical school admissions. Academic Medicine. https://doi.org/10.1097/ACM.0000000000001388

Chen, I., Kurz, J., Pasanen, M., Faselis, C., Panda, M., Staton, L. J., O’Rorke, J., Menon, M., Genao, I., Wood, J., Mechaber, A. J., Rosenberg, E., Carey, T., Calleson, D., \& Cykert, S. (2005). Racial differences in opioid use for chronic nonmalignant pain. Journal of General Internal Medicine, 20(7), 593-598. https://doi.org/10.1111/j. 1525-1497.2005.0106.x

Cohen, J. J., Gabriel, B. A., \& Terrell, C. (2002). The case for diversity in the health care workforce. Health Affairs (Project Hope), 21(5), 90-102. https://doi.org/10.1377/hlthaff.21.5.90

Collins, J. W., \& David, R. J. (2009). Racial disparity in low birth weight and infant mortality. Clinics in Perinatology, 36(1), 63-73. https://doi.org/10.1016/j.clp.2008.09.004 
Cooper, L. A., Roter, D. L., Johnson, R. L., Ford, D. E., Steinwachs, D. M., \& Powe, N. R. (2003). Patient-centered communication, ratings of care, and concordance of patient and physician race. Annals of Internal Medicine, 139(11), 907-916. https://doi.org/10.7326/0003-4819-139-11-200312020-00009

Denson, N., \& Chang, M. J. (2009). Racial diversity matters : The impact of diversity-related student engagement and institutional context. 46(2), 322-353. https://doi.org/10.3102/0002831208323278

Dhalla, I. A., Kwong, J. C., Streiner, D. L., Baddour, R. E., Waddell, A. E., \& Johnson, I. L. (2002). Characteristics of first-year students in Canadian medical schools. Cmaj, 166(8), 1029-1035.

Drwecki, B. B., Moore, C. F., Ward, S. E., \& Prkachin, K. M. (2011). Reducing racial disparities in pain treatment: the role of empathy and perspective-taking. Pain, 152(5), 1001-1006. https://doi.org/10.1016/j.pain.2010.12.005

Flexner, A. (1910). Medical education in the United States and Canada Bulletin Number Four (The Flexner Report). In Carnegie Bulletin.

Goode, C. A., \& Landefeld, T. (2019). The lack of diversity in healthcare : Causes, consequences, and solutions. Journal of Best Practice Health Professional Diversity, 11(2), 73-95.

Gordon, H. S., Street, R. L., Sharf, B. F., \& Souchek, J. (2006). Racial differences in doctors' information-giving and patients' participation. Cancer, 107(6), 1313-1320. https://doi.org/10.1002/cncr.22122

Goyal, M. K., Kuppermann, N., Cleary, S. D., Teach, S. J., \& Chamberlain, J. M. (2015). Racial disparities in pain management of children with appendicitis in emergency departments. JAMA Pediatrics, 169(11), 996-1002. https://doi. org/10.1001/jamapediatrics.2015.1915

Greenwood, B. N., Hardeman, R. R., Huang, L., \& Sojourner, A. (2020). Physician-patient racial concordance and disparities in birthing mortality for newborns. Proceedings of the National Academy of Sciences of the United States of America, 117(35), 21194-21200. https://doi.org/10.1073/pnas.1913405117

Grier, W. H., \& Cobbs, P. M. (1970). Black rage. The Family Coordinator, 19(3). https://doi.org/10.2307/582039

Grumbach, K., \& Mendoza, R. (2008). Disparities in human resources: Addressing the lack of diversity in the health professions. Health Affairs (Project Hope), 27(2), 413-422. https://doi.org/10.1377/hlthaff.27.2.413

Hammond, W. P., Matthews, D., Mohottige, D., Agyemang, A., \& Corbie-Smith, G. (2010). Masculinity, medical mistrust, and preventive health services delays among community-dwelling african-american men. Journal of General Internal Medicine, 25(12), 1300-1308. https://doi.org/10.1007/s11606-010-1481-z

Harper, S., Rushani, D., \& Kaufman, J. S. (2012). Trends in the Black-White life expectancy gap, 2003-2008. JAMA, 307(21), 2257-2259. https://doi.org/10.1001/jama.2012.5059

Hauck, F. R., Tanabe, K. O., \& Moon, R. Y. (2011). Racial and ethnic disparities in infant mortality. Seminars in Perinatology. https://doi.org/10.1053/j.semperi.2011.02.018

Hill, A., Jones, D., \& Woodworth, L. (2018). A doctor like me: Physician-patientrace-match and patient outcomes. SSRN Electronic Journal, 1-41. https://doi.org/10.2139/ssrn.3211276

Jacobs, E. A., Rolle, I., Ferrans, C. E., Whitaker, E. E., \& Warnecke, R. B. (2006). Understanding African Americans' views of the trustworthiness of physicians. Journal of General Internal Medicine, 21(6), 642-647. https://doi.org/ 10.1111/j.1525-1497.2006.00485.x

Joseph, J. (2010). Willingness to seek professional psychological help among Canadians of African descent : A culturally based help-seeking model. University of Windsor.

King, W. D., Wong, M. D., Shapiro, M. F., Landon, B. E., \& Cunningham, W. E. (2004). Does racial concordance between HIV-positive patients and their physicians affect the time to receipt of protease inhibitors? Journal of General Internal Medicine. https://doi.org/10.1111/j.1525-1497.2004.30443.x

Kinlock, B. L., Parker, L. J., Bowie, J. V., Howard, D. L., LaVeist, T. A., \& Thorpe, R. J. (2017). High levels of medical mistrust are associated with low quality of life among black and white men with prostate cancer. Cancer Control, 24(1), 72-77. https://doi.org/10.1177/107327481702400112

Klonoff, E. A., Landrine, H., \& Ullman, J. B. (1999). Racial discrimination and psychiatric symptoms among Blacks. Cultural Diversity and Ethnic Minority Psychology, 5(4). https://doi.org/10.1037/1099-9809.5.4.329

Klonoff, Elizabeth A., \& Landrine, H. (1999). Cross-validation of the schedule of racist events. Journal of Black Psychology, 25(2). https://doi.org/10.1177/0095798499025002006

Lam, J., Phillips, C., \& Okafor, I. (2020). COVID-19: An urgent opportunity to decrease financial barriers to medical school admissions. Canadian Medical Education Journal, May, 3-5. https://doi.org/10.36834/cmej.70219

LaVeist, T. A., \& Carroll, T. (2002). Race of physician and satisfaction with care among African-American patients. Journal of the National Medical Association.

Laveist, T. A., \& Nuru-jeter, A. (2018). The association of doctor-patient race concordance with health services utilization. 24(3), 312-323.

Lynd, S. (1966). The compromise of 1787. Political Science Quarterly, 81(2), 225-250. https://doi.org/10.2307/2147971

MacDorman, M. F., Declercq, E., \& Thoma, M. E. (2017). Trends in maternal mortality by sociodemographic characteristics and cause of death in 27 states and the District of Columbia. Obstetrics and Gynecology. https://doi.org/10. 1097/AOG.0000000000001968 
Meghani, S. H., Brooks, J. M., Gipson-Jones, T., Waite, R., Whitfield-Harris, L., \& Deatrick, J. A. (2009). Patientprovider race-concordance: Does it matter in improving minority patients' health outcomes? Ethnicity and Health, 14(1), 107-130. https://doi.org/10.1080/13557850802227031

Mossey, J. M. (2011). Defining racial and ethnic disparities in pain management. Clinical Orthopaedics and Related Research, 469(7), 1859-1870. https://doi.org/10.1007/s11999-011-1770-9

Mpalirwa, J., Lofters, A., Nnorom, O., \& Hanson, M. D. (2020). Patients, pride, and prejudice: Exploring Black Ontarian physicians' experiences of racism and discrimination. Academic Medicine, 95(11S).

Nanna, M. G., Navar, A. M., Zakroysky, P., Xiang, Q., Goldberg, A. C., Robinson, J., Roger, V. L., Virani, S. S., Wilson, P. W. F., Elassal, J., Veronica Lee, L., Wang, T. Y., \& Peterson, E. D. (2018). Association of patient perceptions of cardiovascular risk and beliefs on statin drugs with racial differences in statin use: Insights from the patient and provider assessment of lipid management registry. JAMA Cardiology, 3(8), 739-748. https://doi. org/10.1001/jamacardio.2018.1511

Nnorom, O., Findlay, N., Lee-Foon, N. K., Jain, A. A., Ziegler, C. P., Scott, F. E., Rodney, P., \& Lofters, A. K. (2019). Dying to learn: A scoping review of breast and cervical cancer studies focusing on Black Canadian women. Journal of Health Care for the Poor and Underserved, 30(4), 1331-1359. https://doi.org/10.1353/hpu.2019.0100

Osseo-asare, A., Balasuriya, L., Huot, S. J., Keene, D., Berg, D., Nunez-smith, M., \& Genao, I. (2018). Minority resident physicians' views on the role of race / ethnicity in their training experiences in the workplace. 1(5), 1-11. https://doi.org/10.1001/jamanetworkopen.2018.2723

Palepu, A., Carr, P. L., Friedman, R. H., Ash, A. S., \& Moskowitz, M. A. (2000). Specialty choices, compensation, and career satisfaction of underrepresented minority faculty in academic medicine. Academic Medicine : Journal of the Association of American Medical Colleges, 75(2), 157-160. https://doi.org/10.1097/00001888-200002000-00014

Pope, J. (2015). Three-fifths compromise. In The Wiley Blackwell Encyclopedia of Race, Ethnicity, and Nationalism. https://doi.org/10.1002/9781118663202.wberen571

Saha, S., Komaromy, M., Koepsell, T. D., \& Bindman, A. B. (1999). Patient-physician racial concordance and the perceived quality and use of health care. Archives of Internal Medicine, 159(9), 997-1004. https://doi.org/10. 1001/archinte.159.9.997

Saha, S., \& Shipman, S. (2006). The rationale for diversity in the health professions : A review of the evidence. U.S. Department of Health and Human Services, Health Resources and Services Administration, Bureau of Health Professions.

Sellers, S., Cherepanav, D., Hanmer, J., Fryback, D. G., \& Palta, M. (2013). Interpersonal discrimination and healthrelated quality of life among black and white men and women in the United States. Quality of Life Research : An International Journal of Quality of Life Aspects of Treatment, Care and Rehabilitation, 22(6), 1307-1312. https://doi.org/10.1007/s11136-012-0258-8

Shen, M. J., Peterson, E. B., Costas-Muñiz, R., Hernandez, M. H., Jewell, S. T., Matsoukas, K., \& Bylund, C. L. (2018). The effects of race and racial concordance on patient-physician communication: A systematic review of the literature. Journal of Racial and Ethnic Health Disparities, 5(1), 117-140. https://doi.org/10.1007/s40615-017-0350-4

Silber, J. H., Rosenbaum, P. R., Ross, R. N., Niknam, B. A., Ludwig, J. M., Wang, W., Clark, A. S., Fox, K. R., Wang, M., Even-Shoshan, O., \& Giantonio, B. J. (2014). Racial disparities in colon cancer survival: A matched cohort study. Annals of Internal Medicine, 161(12), 845-854. https://doi.org/10.7326/M14-0900

Statistics Canada. (2017). Focus on geography series, 2016 census. Statistics Canada.

Staton, L. J., Panda, M., Chen, I., Genao, I., Kurz, J., Pasanen, M., Mechaber, A. J., Menon, M., O’Rorke, J., Wood, J., Rosenberg, E., Faeslis, C., Carey, T., Calleson, D., \& Cykert, S. (2007). When race matters: Disagreement in pain perception between patients and their physicians in primary care. Journal of the National Medical Association, 99(5), 532-538.

Strumpf, E. C. (2011). Racial/ethnic disparities in primary care: The role of physician-patient concordance. Medical Care. https://doi.org/10.1097/MLR.0b013e31820fbee4

Strumpf, E. C., Care, S. M., May, N., \& Strumpf, E. C. (2020). Racial/ethnic disparities in primary care The Role of Physician-Patient Concordance. 49(5), 496-503.

Sue, D. W., Capodilupo, C. M., Torino, G. C., Bucceri, J. M., Holder, A. M. B., Nadal, K. L., \& Esquilin, M. (2007). Racial microaggressions in everyday life: Implications for clinical practice. American Psychologist, 62(4). https:// doi.org/10.1037/0003-066X.62.4.271

Sweeney, C. F., Zinner, D., Rust, G., \& Fryer, G. E. (2016). Race/ethnicity and health care communication. Medical Care, 54(11), 1005-1009. https://doi.org/10.1097/MLR.0000000000000578

Thomas, J. K. (2009). Medical apartheid: The dark history of medical experimentation on Black Americans from colonial times to the present , by Harriet A. Washington . Rural Sociology. https://doi.org/10.1526/003601109789037187

Thompson, R. A., \& Cimbolic, P. (1978). Black students' counselor preference and attitudes toward counseling center use. Journal of Counseling Psychology, 25(6). https://doi.org/10.1037/0022-0167.25.6.570

University of Toronto MD Program. (2021a). Black Student application program. https://applymd.utoronto.ca/blackstudent-application-program

University of Toronto MD Program. (2021b). Community of support. https://applymd.utoronto.ca/community-support 
University of Toronto MD Program. (2021c). Diversity mentorship program and resources. https://medicine.utoronto.ca/ about/diversity-mentorship-program

University of Toronto MD Program. (2021d). Indigenous student application program. https://applymd.utoronto.ca/indigenousstudent-application-program

University of Toronto MD Program. (2021e). Summer mentorship program. https://md.utoronto.ca/SMP

University of Toronto MD Program. (2021f). What is mistreatment? https://md.utoronto.ca/what-mistreatment

UofT Black Medical Students' Association. (2020). Unofficial guide to Canadian Medical School. https:// canadianguidetomedschool.com/index.html

Valantine, H. A., \& Collins, F. S. (2015). National Institutes of Health addresses the science of diversity. 112(40), 12240-12242. https://doi.org/10.1073/pnas.1515612112

Veenstra, G. (2019). Black, White, Black and White: mixed race and health in Canada. Ethnicity \& Health, 24(2), $113-124$. https://doi.org/10.1080/13557858.2017.1315374

Veenstra, G., \& Patterson, A. C. (2016). Black-White health inequalities in Canada. Journal of Immigrant and Minority Health, 18(1), 51-57. https://doi.org/10.1007/s10903-014-0140-6

Villarosa, L. (2018). Why America's black mothers and babies are in a life-or-death crisis. New York Times Magazine.

Wallace, M., Crear-Perry, J., Richardson, L., Tarver, M., \& Theall, K. (2017). Separate and unequal: Structural racism and infant mortality in the US. Health and Place. https://doi.org/10.1016/j.healthplace.2017.03.012

Publisher's Note Springer Nature remains neutral with regard to jurisdictional claims in published maps and institutional affiliations. 